\title{
Produtividade, incidência de podridões de colmo e qualidade de grãos de milho cultivados sob diferentes arranjos espaciais e densidades de plantas
}

\author{
Productivity, incidence of stalk rot and quality of cultivated corn kernels under different spatial arrangements \\ and plant densities
}

\section{Evandro Spagnollo*, João Américo Wordell Filho, Cristiano Nunes Nesi}

Recebido em 05/02/2016 / Aceito em 16/05/2016

\section{RESUMO}

A produtividade e a qualidade do milho podem ser influenciadas pela ocorrência de doenças, cuja intensidade pode ser afetada por fatores ambientais e por práticas fitotécnicas. Dessa forma, o objetivo deste estudo foi avaliar o efeito do arranjo de plantas de milho e da densidade de semeadura no rendimento de grãos e na massa de mil grãos, bem como na incidência de podridões da base do colmo, grãos ardidos e de fungos associados aos grãos. $\mathrm{O}$ estudo foi realizado nas safras 2010/2011 e 2012/2013, em Chapecó, SC, Brasil. Os tratamentos foram constituídos por diferentes espaçamentos entre linhas $(0,45$ e $0,80 \mathrm{~m})$ e densidades de plantas $(50,60,70,80$ e 90 mil plantas $\mathrm{ha}^{-1}$ ), com delineamento de blocos casualizados em esquema de parcelas sub-subdivididas. Na parcela principal foram testados dois híbridos simples de milho de ciclo precoce (P30F53H e DKB 240H), nas subparcelas os espaçamentos e nas sub-subparcelas as populações de plantas. As unidades experimentais consistiram de seis linhas de $4 \mathrm{~m}$ de comprimento. O rendimento de grãos no espaçamento $0,45 \mathrm{~m}$ foi $29,65 \%$ superior ao obtido no espaçamento $0,80 \mathrm{~m}$ para os híbridos estudados. A massa de mil grãos e a incidência de grãos ardidos reduziram com o aumento da população de plantas. No entanto, a incidência de Fusarium verticillioides, Fusarium graminearum e Stenocarpella maydis não foi influenciada pelas populações de plantas nem pelos espaçamentos testados nas condições do presente estudo.

PALAVRAS-CHAVES: Zea mays, população de plantas, Fusarium verticillioides, podridão da base do colmo.

\section{ABSTRACT}

The productivity and quality of maize can be influenced by the occurrence of diseases. The intensity is affected by environmental factors and phytotechnical practices. Thus, this study was carried out to evaluate the effect of arrangement of plants and plant density on grain yield and thousand grain weight and incidence of stalk rot and fungi associated with grains. The work was conducted during the 2010/2011 and 2012/2013 seasons in Chapecó, SC, Brazil. The treatments consisted of different row spacings $(0.45$ and $0.80 \mathrm{~m})$ and plant densities (50, $60,70,80$ and 90 thousand plants ha $\left.{ }^{-1}\right)$ with a design of randomized blocks in subdivided sub plots. In the main plot two simple hybrids of corn early cycle were tested (P30F53H and DKB 240H), the subplots and the spacing in the sub-subplot plant populations. The experimental units consisted of six lines of 4 $\mathrm{m}$ in length. The yield on the $0.45 \mathrm{~m}$ spacing was $29.65 \%$ higher than in the $0.80 \mathrm{~m}$ spacing for the studied hybrids. The mass of a thousand grains and the incidence of rot grains decreased with an increase in plant population. However, the incidence of Fusarium verticillioides, Fusarium graminearum and Stenocarpella maydis was not affected by plant populations or by spacing tested under the conditions of this study.

KEYWORDS: Zea mays, population, Fusarium verticillioides, stalk rot.

\section{INTRODUÇÃO}

O milho (Zea mays L.) é uma das principais culturas destinadas à alimentação humana e animal

Empresa de Pesquisa Agropecuária e Extensão Rural de Santa Catarina, Chapecó, SC, Brasil.

*Autor para correspondência <spagnollo@epagri.sc.gov.br> 
devido à sua composição química e alto valor nutritivo. Além de suas aplicações alimentícias, esse cereal é utilizado como matéria-prima para a produção de diversos tipos de produtos. Em Santa Catarina, são produzidas anualmente mais de 3,5 milhões de toneladas de milho, porém devido à grande demanda da cadeia agroindustrial, em 2015 o déficit chegou a 2,5 milhões de toneladas, podendo ser maior ainda em 2016 (CEPA 2016).

Assim, aprimorar técnicas que facilitem o cultivo do milho para proporcionar incremento de produtividade é uma premissa da pesquisa agropecuária. Dentre as alternativas para manejar a cultura do milho, destaca-se o cultivo com espaçamento reduzido entre linhas, mantendo-se a mesma densidade de plantas. Desta forma, as plantas de milho ficam com melhor distribuição espacial, reduzindo a competição intra plantas (BALBINOT JUNIOR \& FLECK 2005). Espaçamentos adequadamente reduzidos entre linhas de plantas de milho aumentam a capacidade de interceptação de radiação solar, aproveitamento de água e absorção de nutrientes pelas plantas, e consequentemente produtividade de grãos (SANGOI \& SILVA 2010).

Estudos têm demonstrado também que a distribuição espacial das plantas de milho pode causar uma redução na competição de plantas daninhas e, consequentemente, na necessidade de aplicação de herbicidas (MARCHÃO et al. 2005). Por outro lado, menores incidências de doenças, incluindo as podridões da base do colmo (PBC), foram verificadas em estudos que utilizaram menores densidades populacionais (CASA et al. 2007). Neste sentido, pode-se optar por híbridos mais adaptados ao maior ou menor adensamento conforme for a opção de plantio para a lavoura. Plantas de porte mais baixo podem suportar a semeadura em densidades maiores e os tratos culturais, se bem aplicados, evitam que o microclima criado com o aumento na população de plantas favoreça a incidência de doenças.

As principais espécies de fungos causadoras de PBC relatadas no Brasil são: Colletotrichum graminicola (Ces), Stenocarpella maydis (Berk.) [Sin. Diplodia maydis (Berk.), Stenocarpella macrospora Earle [Sin. D. macrospora Earle in Bull.], Fusarium graminearum Schwabe (Gibberella zeae Schw.) e Fusarium verticillioides [Sin.= Fusarium moniliforme Sheld (Gibberella fujikuroi Sawada)] (WORDELL FILHO \& CASA 2010). Os fatores que provavelmente determinaram o aumento das PBC devem estar relacionados com: competição por nutrientes, relação N e K (FOLEY \& WERNHAM 1957), desequilíbrio nutricional entre os colmos e as espigas e também disponibilidade de água, conforme sugerido por ZUBER et al. (1957); SHURTLEFF (1992), além da nebulosidade prolongada (FANCELLI 1994). Estes fatores são responsáveis pela rápida e prematura manifestação de senescência nos tecidos, favorecendo o aumento da suscetibilidade ao ataque de fungos causadores de PBC (DEACON 1997).

Alguns desses fungos também estão associados aos grãos ardidos (GA), principalmente quando colonizam a espiga na fase de enchimento de grãos. Pode também haver a presença de micotoxinas nos grãos, incluindo as fumonisinas (WORDELL FILHO \& SPAGNOLLO 2013). Os GA constituem-se em uma das principais causas da redução da qualidade do milho. Vários fatores podem afetar a incidência de GA em híbridos de milho, incluindo a resistência genética do híbrido ou variedade, os regimes de precipitação pluviométrica de cada localidade (COSTA et al. 2010), insetos, tipo de solo e nutrição.

Considerando as condições fitotécnicas no cultivo do milho, o objetivo deste trabalho foi avaliar o efeito de diferentes espaçamentos e densidades de semeadura no rendimento e na qualidade de grãos de milho, bem como na incidência de podridão da base do colmo e de grãos ardidos, além da presença de patógenos associados aos grãos.

\section{MATERIAL E MÉTODOS}

O estudo foi conduzido nas safras de 2010/11, 2011/12 e 2012/13 no município de Chapecó, SC, Brasil (27 06' 34' S; 52 40' $18^{\circ}$ ' O e altitude de 623 metros), em área com solo do tipo Latossolo Vermelho distroférrico típico mantido sob sistema de plantio direto com monocultivo de milho nos últimos quatro anos e com histórico de ocorrência de podridões de colmo. Segundo a classificação climática de Köppen, a região apresenta um clima mesotérmico úmido com verão quente $(\mathrm{Cfa})$. Devido à ocorrência de estiagem intensa na safra 2011/12, a produtividade foi muito baixa e os dados obtidos não foram considerados. $\mathrm{Na}$ Figura 1 encontram-se informações referentes à precipitação pluviométrica, insolação, umidade relativa e temperatura média. Esses dados foram obtidos na Estação de Agrometeorologia do Cepaf/ Epagri de Chapecó, SC, para o período de cultivo de milho nas safras 2010/11 e 2012/13. 


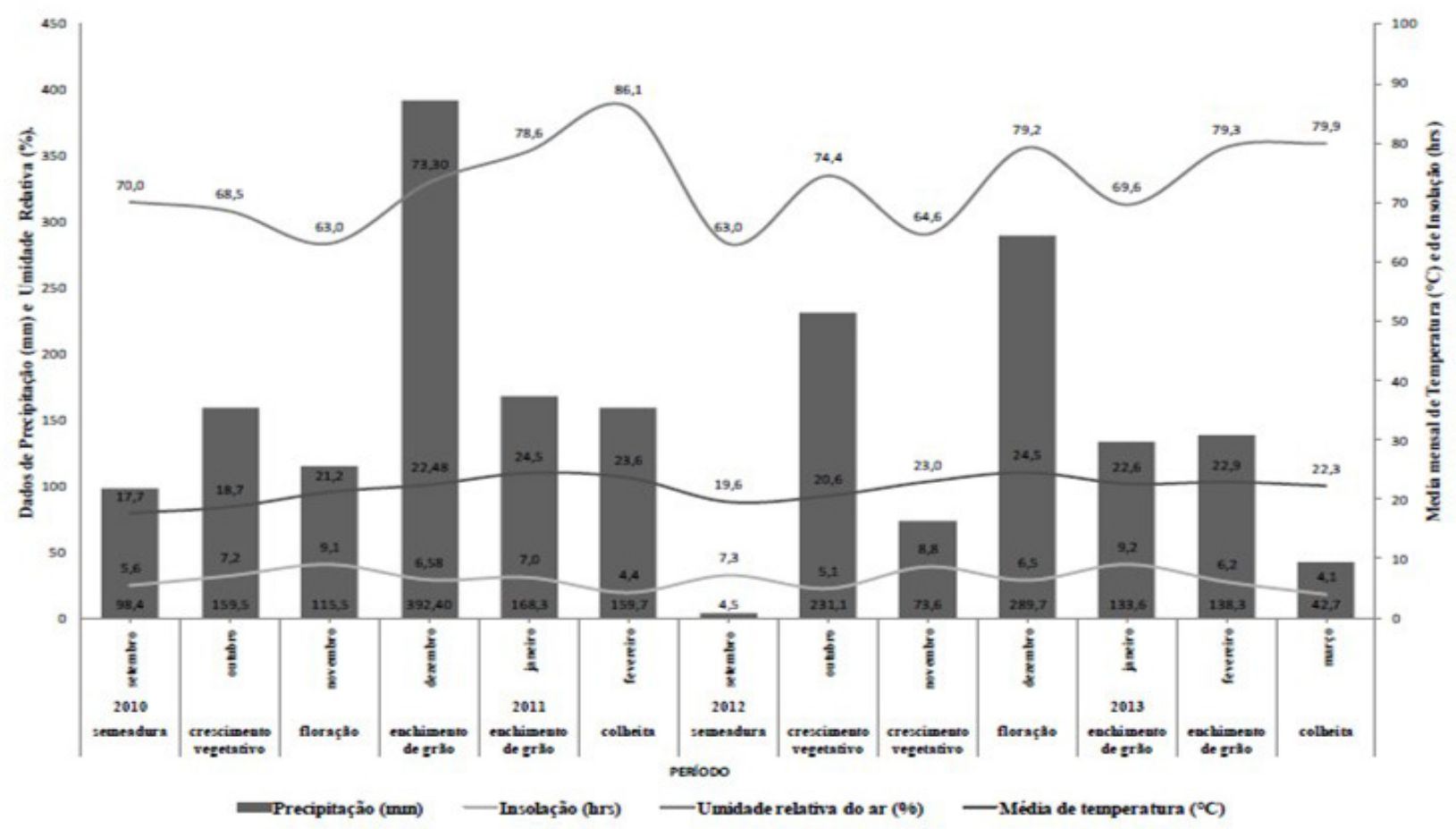

Figura 1 - Condições ambientais verificadas durante o ciclo da cultura do milho nas safras 2010/11 e 2012/13. Chapecó, SC. 2014.

Figure 1 - Environmental conditions observed during the 2010/11 and 2012/13 maize crop cycle. Chapecó, SC. 2014.

O delineamento experimental foi em blocos casualizados com quatro repetições no esquema de parcelas sub-subdivididas. Os espaçamentos utilizados foram de 0,45 e $0,80 \mathrm{~m}$ entre linhas, com densidades equivalentes a 50,60,70, 80 e 90 mil plantas $\mathrm{ha}^{-1}$. Na parcela principal foram testados dois híbridos simples de milho de ciclo precoce (P30F53H e DKB 240H), nas subparcelas os espaçamentos e nas sub-subparcelas as diferentes densidades de semeadura. As unidades experimentais consistiram de seis linhas de $4 \mathrm{~m}$ de comprimento, considerando as duas linhas centrais como área útil das parcelas.

As semeaduras foram realizadas manualmente em 15/09/2010 e 20/09/2012, 30 dias após a dessecação da cobertura de inverno (Secale cereale L.), com o herbicida glifosato (1.400 mL i.a. ha $\left.{ }^{-1}\right)$. A adubação com nitrogênio, fósforo e potássio foi realizada de acordo com a análise de solo, para uma expectativa de rendimento de $12.000 \mathrm{~kg} \mathrm{ha}^{-1}$ (CQFS - RS/SC 2004), utilizando-se como fonte de nutrientes a fórmula comercial NPK 8-20-20, ureia, super fosfato triplo (SFT), cloreto de potássio $(\mathrm{KCl})$, totalizando uma aplicação equivalente a $60 \mathrm{~kg} \mathrm{ha}^{-1}$ de $\mathrm{N}, 120 \mathrm{~kg} \mathrm{ha}^{-1}$ de $\mathrm{P}_{2} \mathrm{O}_{5}$ e $110 \mathrm{~kg} \mathrm{ha}^{-1}$ de $\mathrm{K}_{2} \mathrm{O}$. A adubação nitrogenada em cobertura foi realizada em duas aplicações, aos
25 e 40 dias após a emergência, em ambas as safras, totalizando $130 \mathrm{~kg} \mathrm{ha}^{-1}$ de $\mathrm{N}$ (utilizou-se a ureia como fonte de N). Como prevenção ao ataque de pragas na fase de emergência das plântulas, as sementes foram tratadas com o inseticida tiametoxana $(0,4 \mathrm{~g}$ i.a kg-1 semente). Para manejo de plantas daninhas em pósemergência, foi aplicada uma mistura de atrazina $\left(1.400 \mathrm{~mL}\right.$ i.a. ha $\left.{ }^{-1}\right)$ e metolacloro $(2.100 \mathrm{~mL}$ i.a. $\left.\mathrm{ha}^{-1}\right)$. A densidade de plantas foi estabelecida por meio de desbaste manual, quando as plantas apresentavam três folhas. Para o controle da lagarta-do-cartucho, Spodoptera frugiperda (Smith) (Lepidoptera: Noctuidae), foi aplicada a mistura dos inseticidas diflubenzuron (100 $\left.\mathrm{g} \mathrm{ha}^{-1}\right)$ e metomil $\left(129 \mathrm{~g} \mathrm{ha}^{-1}\right)$ aos 45 dias após a emergência, em ambas as safras.

A incidência das PBC foi quantificada seguindo a metodologia proposta por REIS et al. (1998), considerando plantas sintomáticas aquelas que apresentaram descoloração do primeiro ou do segundo entrenó e/ou aquelas com menor resistência do colmo à pressão dos dedos polegar e indicador, sendo realizada 15 dias antes da colheita. Os colmos sintomáticos foram cortados e levados ao laboratório, onde foram retirados dois fragmentos de $\pm 1 \mathrm{~mm}^{2}$ do tecido interno da medula de cada colmo na região 
próxima ao nó. Os fragmentos foram desinfestados com hipoclorito de sódio a $1 \%$ durante três minutos, e transferidos para caixas de poliestireno do tipo gerbox, contendo meio de cultura BDA (batata-dextrose-ágar $=$ Merck: $40 \mathrm{~g} \mathrm{~L}^{-1}$ ) $+\mathrm{A}$ (antibiótico $=200 \mathrm{mg} \mathrm{L}^{-1} \mathrm{de}$ sulfato de estreptomicina). Os dados obtidos foram expressos pela percentagem de incidência de $\mathrm{PBC}$, especificando os fungos associados.

Para determinação do rendimento de grãos e massa de mil grãos (MMG), as espigas foram debulhadas manualmente e os grãos foram secados em estufa até atingirem a umidade constante de $13 \%$. A avaliação de grãos ardidos (GA) foi obtida pela separação manual de grãos sintomáticos e grãos sadios, em uma amostra de $250 \mathrm{~g}$ de grãos em cada parcela (BRASIL 1996). Os GA foram pesados e a incidência de grãos sintomáticos foi expressa em percentagem. Também foi verificado a presença de fungos nos grãos, utilizando-se quatro repetições de 400 grãos por parcela, os quais foram desinfestados com hipoclorito de sódio a $50 \%$ e transferidos para caixas de poliestireno do tipo gerbox em meio $\mathrm{BDA}+\mathrm{A}$. O material foi incubado durante sete dias sob condições controladas (temperatura de $25 \pm$ $1{ }^{\circ} \mathrm{C}$ e fotoperíodo de $12 \mathrm{~h}$ ). Foram considerados infectados os grãos que desenvolveram colônias e/ou estruturas de fungos, os quais foram identificados em microscópio estereoscópico, seguindo a metodologia adotada por WORDELL FILHO \& SPAGNOLLO (2013). As espécies do gênero Fusarium infectantes de colmos de milho foram diferenciadas por caracteres taxonômicos de classificação agrupadas nas chaves sinóticas de NELSON et al. (1983).

Os dados foram submetidos à análise de variância para verificar o efeito de híbridos, espaçamentos, populações e suas interações. Quando o efeito de população foi significativo, ajustou-se um modelo de regressão linear simples, com a população de plantas como variável explicativa. As análises foram realizadas utilizando-se o programa $R$ ( $R$ DEVELOPMENT CORE TEAM 2014).

\section{RESULTADOS E DISCUSSÃO}

$\mathrm{O}$ efeito dos fatores e suas interações podem ser observados pelos valores da significância apresentados na análise de variância (Tabela 1), enquanto as estimativas dos parâmetros das equações de regressão estão detalhadas na Tabela 2. Na safra 2010/11, para o rendimento de grãos foi significativa à interação entre o espaçamento entre linhas e a densidade de semeadura, enquanto que na safra $2012 / 13$ foram significativos $(p<0,05)$ o efeito de híbridos e da densidade de plantas (Tabela 1).

Na safra 2010/11, para demonstrar a relação do rendimento de grãos em função das diferentes populações de plantas nos espaçamentos de $0,45 \mathrm{~m}$ e $0,80 \mathrm{~m}$, foram ajustadas as equações de regressão linear simples, as quais estimaram maior resposta de rendimento no espaçamento de $0,80 \mathrm{~m}$, alcançando $71,16 \mathrm{~kg} \mathrm{ha}^{-1}$ para cada 1.000 plantas adicionais por hectare (Tabela 2). Nesse espaçamento, apesar do incremento no rendimento ser maior, a população deveria ser de aproximadamente 40.000 plantas a mais para que o rendimento fosse igual ao obtido no espaçamento entre linhas de $0,45 \mathrm{~m}$. Esse efeito é decorrente, possivelmente, da arquitetura da planta de milho, ou seja, da angulação das folhas, que permite a entrada de luz entre as folhas, ou seja, resposta da maior interceptação de luminosidade na produtividade de grãos (SANGOI \& SILVA 2010). Este resultado diverge daqueles obtidos por SERPA et al. (2008), que não detectaram aumento da produtividade do milho pela redução do espaçamento entre linhas em semeadura do cedo na Depressão Central do RS, avaliando dois espaçamentos, 0,4 e $0,8 \mathrm{~m}$ entre linhas e dois híbridos de milho, P32R48 e NB 3234. Efeito semelhante foi obtido na safra 2012/13, mas não foi observado efeito de espaçamento no rendimento de grãos. Os resultados podem ter sido influenciados pela ocorrência de menor precipitação pluviométrica na fase de crescimento vegetativo/floração, se comparado à safra 2010/11 (Figura 1). Na safra 2012/2013 somente ocorreu efeito de densidades de semeadura no rendimento do milho, com incremento de $25 \mathrm{~kg}$ ha $^{-1}$ para cada 1.000 plantas adicionais, e também efeito do genótipo utilizado, com maior produtividade no híbrido P30F53H (11200 kg ha-1) em relação ao híbrido DKB $240 \mathrm{H}\left(10710 \mathrm{~kg} \mathrm{ha}^{-1}\right)$. Cabe ressaltar, no entanto, que em condições de estresse hídrico, o aumento da densidade de semeadura é prejudicial ao rendimento de grãos, como constatado por TETIOKAGHO \& GARDNER (1988).

Para a variável MMG houve efeito significativo apenas de população na safra 2010/11 (Tabela 1), ajustando-se a equação que estima efeito negativo do aumento da população com redução de $0,59 \mathrm{~g}$ na MMG para cada 1.000 plantas adicionais (Tabela 2). Essa constatação está de acordo com os resultados de SANGOI \& SILVA (2010), que verificaram redução 
Tabela 1 - Significância dos fatores considerados na análise de variância dos dados de rendimento de grãos (REND), massa de mil grãos (MMG), podridão da base do colmo (PBC) e grãos ardidos (GA), em função da densidade de plantas, do espaçamento entre linhas e dos híbridos de milho. Chapecó, SC. 2014.

Table 1 - Significance of the factors considered in the variance analysis of grain yield, thousand grain weights, stem rot and damaged kernels, depending on the plant density, row spacing and maize hybrid. Chapecó, SC. 2014.

\begin{tabular}{lllll}
\hline Fatores & REND. & MMG & PBC & GA \\
\hline & \multicolumn{4}{c}{ p-valor* } \\
& \multicolumn{4}{c}{ Safra 2010/2011 } \\
Blocos & 0,0599 & 0,2784 & 0,3162 & 0,6701 \\
Híb. & 0,5371 & 0,7634 & 0,1261 & 0,2571 \\
Esp. & 0,0333 & 0,3761 & 0,8289 & 0,2968 \\
Híb. x Esp. & 0,2415 & 0,2064 & 0,2879 & 0,7036 \\
Dens. & $<0,001$ & $<0,001$ & 0,0806 & 0,9847 \\
Dens. x Híb. & 0,5576 & 0,3059 & 0,0090 & 0,1978 \\
Dens. x Esp. & 0,0204 & 0,0725 & 0,2334 & 0,3460 \\
Dens. x Híb. x Esp. & 0,3262 & 0,5771 & 0,9300 & 0,5232
\end{tabular}

Safra 2012/2013

$\begin{array}{lllll}\text { Blocos } & <0,001 & 0,0091 & 0,1230 & 0,3414 \\ \text { Híb. } & 0,0002 & 0,0634 & 0,6161 & 0,0083 \\ \text { Esp. } & 0,1345 & 0,8330 & 0,0028 & 0,1585 \\ \text { Híb. x Esp. } & 0,8767 & 0,3767 & 0,9362 & 0,6531 \\ \text { Dens. } & 0,0085 & 0,0719 & 0,1716 & 0,9214 \\ \text { Dens. x Híb. } & 0,4231 & 0,9565 & 0,6855 & 0,3833 \\ \text { Dens. x Esp. } & 0,1211 & 0,4916 & 0,6654 & 0,8463 \\ \text { Dens. x Híb. x Esp. } & 0,8987 & 0,7535 & 0,3112 & 0,8996\end{array}$

Híb. = Híbridos (P30F53H e DKB 240H); Esp. = Espaçamentos entre linhas $(0,45 \mathrm{~m}$ e 0,80 m); Dens. = Densidade de plantas $\left(50,60,70,80\right.$ e 90 mil plantas ha $\left.{ }^{-1}\right)$. ${ }^{*}$ Valores menores que 0,05 são considerados significativos a $5 \%$ de probabilidade pelo teste $\mathrm{F}$ na análise de variância.

da MMG com o aumento da população de plantas. Com altas densidades de plantas, aumenta-se a competição entre plantas por água, nutrientes e luz, diminuindo a massa individual dos grãos produzidos (PEIXOTO et al. 1997).

Para as PBC houve efeito significativo da interação entre populações e híbridos (Tabela 1), com resposta linear apenas para o híbrido DKB $240 \mathrm{H}$, demonstrando aumento de $0,54 \%$ de PBC para cada
1.000 plantas a mais na população (Tabela 2). Quando a densidade de plantas for maior, ocorrem menor penetração da radiação solar e circulação de ar entre as plantas, prolongando o período de molhamento nas folhas e colmos. Neste sentido, CASA et al. (2007) constataram aumento na incidência de podridões de colmo em dois híbridos de milho, Speed e o AG 303 , pelo incremento na densidade de plantas. $\mathrm{Na}$ safra 2012/13 houve efeito significativo apenas de 
espaçamento, com maior incidência das doenças no espaçamento $0,45 \mathrm{~m}(53,2 \%)$ em relação a $0,80 \mathrm{~m}$ $(42,7 \%)$.

A principal doença detectada nos colmos de milho foi a podridão-de-diplodia, causada pelo fungo $S$. maydis, incidindo em $38,75 \%$ e 48 , $60 \%$ das amostras nas safras 2010/11 e 2012/13, respectivamente. Outros fungos isolados nas amostras foram $F$. verticillioides $(1,66 \%$ e $9,68 \%)$, F. graminearum $(2,50 \%$ e $4,30 \%), S$. macrospora $(10,00 \%$ e $8,20 \%)$ e Cephalosporium sp. $(0,42 \%$ e $0,04 \%$ ), respectivamente, para as safras $2010 / 11$ e
2012/13. Apesar do grande número de patógenos envolvidos com as $\mathrm{PBC}$ na cultura do milho, não foi observado à incidência da podridão do colmo causada pelo fungo $C$. graminicola nas amostras coletadas. De acordo com GATCH \& MUNKOLD (2002), apesar de muitos desses patógenos incidirem simultaneamente na cultura do milho, um grupo está mais frequentemente associado à podridão do colmo em determinada região. Também a dominância das espécies, e a sua diversidade, podem ser alteradas tanto dentro da época de desenvolvimento como gradualmente através do tempo com mudanças de

Tabela 2 - Estimativas dos parâmetros da equação de regressão linear simples ( $\mathrm{y}=\mathrm{a}+\mathrm{bx})$ ajustado aos dados de rendimento de grãos, massa de mil grãos, podridão da base do colmo, em função da densidade de plantas, do espaçamento entre linhas e do híbrido de milho. Abaixo das estimativas (entre parênteses), observam-se os limites do intervalo com 95\% de confiança para as estimativas. Chapecó, SC. 2014.

Table 2 - Estimates of the parameters of the linear regression equation $(y=a+b x)$ adjusted to the yield, thousand grain weight, stem rot, depending on plant density, row spacing and maize hybrid. Below estimates (in parentheses), observe the range limits with 95\% confidence for the estimates. Chapeco, SC. 2014.

\begin{tabular}{|c|c|c|c|c|}
\hline \multirow[b]{2}{*}{ Safra } & \multirow[b]{2}{*}{ Espaçamento/Híbrido } & \multicolumn{3}{|c|}{ Estimativa* } \\
\hline & & $\begin{array}{c}\mathrm{a} \\
\text { (LI; LS) }\end{array}$ & $\begin{array}{c}\mathrm{b} \\
(\mathrm{LI} ; \mathrm{LS})\end{array}$ & $\mathrm{R}^{2}$ \\
\hline \multirow{3}{*}{$2010 / 2011$} & & \multicolumn{3}{|c|}{ Rendimento de grãos $\left(\mathrm{kg} \mathrm{ha}^{-1}\right)$} \\
\hline & $0,45 \mathrm{~m}$ & $\begin{array}{c}12.311 \\
(11.708 ; 12.914)\end{array}$ & $\begin{array}{c}20,44 \\
(12,00 ; 28,89)\end{array}$ & 0,95 \\
\hline & $0,80 \mathrm{~m}$ & $\begin{array}{c}9.495 \\
(6.241 ; 12.750)\end{array}$ & $\begin{array}{c}71,16 \\
(25,59 ; 116,74)\end{array}$ & 0,89 \\
\hline \multirow[t]{2}{*}{$2012 / 2013$} & & $\begin{array}{c}9.201 \\
(8.891 ; 9.510)\end{array}$ & $\begin{array}{c}25,03 \\
(20,69 ; 29,37)\end{array}$ & 0,98 \\
\hline & & \multicolumn{3}{|c|}{ Massa mil grãos (g) } \\
\hline \multirow[t]{2}{*}{$2010 / 2011$} & - & $\begin{array}{c}383,90 \\
(365,61 ; 402,21)\end{array}$ & $\begin{array}{c}-0,59 \\
(-0,85 ;-0,33)\end{array}$ & 0,95 \\
\hline & & \multicolumn{3}{|c|}{ Podridão da base do colmo (\%) } \\
\hline $2010 / 2011$ & DKB $240 \mathrm{H}$ & $\begin{array}{c}4,39 \\
(-18,31 ; 27,10)\end{array}$ & $\begin{array}{c}0,54 \\
(0,22 ; 0,86)\end{array}$ & 0,79 \\
\hline
\end{tabular}

"y=a+bx em que " $y$ " é a variável resposta, "a" é o intercepto e "b" o coeficiente angular da reta; LI e LS correspondem aos limites inferior e superior do intervalo com $95 \%$ de confiança para as estimativas dos parâmetros. 
práticas culturais, introdução de híbridos e mudanças climáticas. Segundo DODD (1980b), raramente uma única espécie de fungo é o agente causal das podridões do colmo do milho. A senescência precoce dos tecidos, fator que acelera a manifestação dos sintomas das PBC, está relacionada com o teor de carboidratos e a translocação de elementos minerais do solo às plantas e do colmo para as espigas (LEOPOLD 1961). Assim, certamente, em lavouras onde é suprida a demanda nutricional, ocorre o retardamento dos sintomas das $\mathrm{PBC}$ em razão do equilíbrio nutricional entre colmo e espiga. Entretanto, a duração da translocação para o grão não é a mesma entre plantas com PBC e plantas sadias (DODD 1980a). No presente trabalho, nas duas safras avaliadas, no período compreendido entre o crescimento vegetativo e enchimento de grãos não ocorreu déficit hídrico (Figura 1), e assim, provavelmente não ocorreu problemas com o suprimento de nutrientes.

Conforme ZUBER et al. (1957), a quantidade de minerais, celulose, potássio e sílica no colmo de milho está associada à fragilidade do colmo à infecção por $S$. maydis e $F$. graminearum. Para as espécies de F. verticillioides e F. subglutinans, também têm sido encontrados genótipos de milho que mostraram reações diferentes às podridões do colmo. Esses autores observaram que híbridos com maior resistência às $\mathrm{PBC}$ apresentavam pigmentação púrpura a roxo-intensa da epiderme do colmo. Além dos fatores já mencionados, a presença de restos culturais, ferimentos causados por insetos e as condições edafoclimáticas, especialmente o menor período de insolação em ambas as safras, levou, em hipótese, à menor exposição dos conídios à radiação solar e à desidratação, conforme demonstrado por DEACON (1997), que afirma ser essa a principal causa da perda de viabilidade dos esporos de $S$. macrospora. Essa condição climática associada à baixa umidade relativa do ar, provavelmente foram as condições limitantes ao desenvolvimento, assemelhando-se ao relatado por DEL RIO (1990), que em umidade relativa do ar inferior a $50 \%, S$. macrospora produz mais micélio do que $S$. maydis, podendo infectar a planta de milho em qualquer estádio de desenvolvimento.

Para a variável grãos ardidos (GA), na safra 2010/11, ocorreu em média $8,80 \%$ de incidência, mas não houve efeito significativo dos fatores avaliados. Este resultado não está de acordo ao encontrado por DEACON (1997), que mencionam o aumento de GA com o aumento da população de plantas. Já em estudo conduzido por COSTA et al. (2010), não foram verificadas diferenças significativas na incidência de GA em função do espaçamento, quando utilizado espaçamentos entre 0,45 e 0,70 m entre linhas. Esses mesmos autores relatam que existe influência da densidade de semeadura e dos híbridos utilizados na incidência de GA, citando que o aumento da densidade de semeadura de 50 para 75 mil plantas ha ${ }^{-1}$ aumenta a incidência de grãos ardidos. Entretanto, no presente estudo na safra 2012/13 foi observada diferença significativa entre híbridos com $48,6 \%$ de GA para DKB $240 \mathrm{H} \mathrm{e} \mathrm{47,3 \%} \mathrm{para} \mathrm{o} \mathrm{híbrido} \mathrm{P30F53H.}$ Diferenças na incidência de GA estão relacionadas às características genéticas na suscetibilidade a pragas e doenças dos híbridos (MARCONDES 2012), às densidades de plantas (CASA et al. 2007) e à precipitação pluviométrica durante o enchimento de grãos. No presente trabalho os resultados corroboram com os obtidos por RIBEIRO et al. (2005), que obteve diferentes incidências de GA quando comparadas diferentes safras agrícolas. Os resultados obtidos no presente estudo também corroboram com os obtidos no trabalho onde foi avaliado a incidência de GA, podridões da base do colmo (PBC) e a produtividade de três híbridos de milho (Status TL, DKB 390 e BRS 1035), cultivados em três densidades de plantas $\left(60,75\right.$ e 90 mil plantas ha $\left.{ }^{-1}\right)$, com duas épocas de colheita (MARCONDES 2012). Neste trabalho, foi concluído que a densidade de plantas não influenciou na incidência de GA em nenhum dos experimentos, mas aumentou a incidência de PBC.

Os fungos identificados em grãos de milho foram $F$. verticillioides, $F$. graminearum e $S$. maydis com incidência média de $53 \%, 1,20 \%$ e 1,24\%, respectivamente, para a safra de $2010 / 11$, e média de $35,59 \%, 0,07 \%$ e $1,04 \%$, respectivamente, para a safra de 2012/13. Assim, no período de setembro de 2010 a fevereiro de 2011, quando ocorreu a precipitação pluviométrica $(1.023,30 \mathrm{~mm})$ superior do que na safra 2012/13 (913,50 mm), determinou maior incidência de fungos associados aos grãos. A maior diferença pluviométrica entre as safras ocorreu no período de enchimento de grãos até a maturação fisiológica, quando o volume de chuva no primeiro ano foi 2,28 vezes superior ao verificado na safra 2012/13 (Figura 1). Além disso, a temperatura média nesse mesmo período em 2010/11 foi aproximadamente $1{ }^{\circ} \mathrm{C}$ superior ao mesmo período na safra 2012/13. A influência da temperatura tem sido estudada para F. verticillioides, mostrando-se estar adaptado a uma 
ampla faixa de temperatura $\left(20\right.$ a $\left.25^{\circ} \mathrm{C}\right)$ (CASTELLÁ et al. 1999), faixa também observada nas safras do presente estudo.

A alta incidência de $F$. verticillioides corrobora com os resultados obtidos por WORDELL FILHO \& SPAGNOLLO (2013), que verificaram que esse é o principal agente causal de GA e de PBC no Sul do Brasil. Esses resultados colaboram com a hipótese que não existe uma correlação entre a incidência e espécime do patógeno, $F$. verticillioides e $S$. maydis, que incidem nos grãos e colmos de plantas de milho, provavelmente devido às condições ambientais, fonte de inóculo diferenciadas entre às doenças e mecanismos de patogenicidade diferentes entre os fungos.

\section{CONCLUSÕES}

O rendimento de grãos no espaçamento $0,45 \mathrm{~m}$ foi $29,65 \%$ superior ao encontrado no espaçamento $0,80 \mathrm{~m}$.

A massa de mil grãos reduz com o aumento da população de plantas.

Somente o híbrido DKB 240 apresentou aumento das podridões da base do colmo com o aumento da população de plantas.

A incidência de grãos ardidos e de Fusarium verticillioides, Fusarium graminearum e Stenocarpella maydis em grãos de milho não foram influenciadas pelo arranjo espacial e densidade de plantas de milho nas condições do presente trabalho.

\section{REFERÊNCIAS}

BALBINOT JUNIOR AA \& FLECK NG. 2005. Competitividade de dois genótipos de milho (Zea mays) com plantas daninhas sob diferentes espaçamentos entre fileiras. Planta Daninha 23: 415-421.

BRASIL. 1996. Portaria $n^{\circ} 11$ de 12 de abril de 1996. Estabelece critérios complementares para classificação do milho. Brasília: Diário Oficial da União. n. 72.

CASA RT et al. 2007. Incidência de podridões do colmo, grãos ardidos e rendimento de grãos de híbridos de milho submetidos ao aumento na densidade de plantas. Summa Phytopathologica 33: 353-357.

CASTELLÁ G et al. 1999. Effect temperature, incubation period and substrate on production of fusaproliferin by Fusarium subglutinans ITEM 2404. Natural Toxins 7: 129132.

CENTRO DE SOCIOECONOMIA E PLANEJAMENTO (CEPA). 2016. Boletim agropecuário. Florianópolis: Epagri 34: 17-19.
COMISSÃO DE QUÍMICA E FERTILIDADE DO SOLO - CQFS - RS/SC. 2004. Manual de adubação e calagem para os estados do Rio Grande do Sul e Santa Catarina. 10 ed. Porto Alegre, 400p.

COSTA RV et al. 2010. Recomendações de cultivares de milho para a resistência a grãos ardidos. Sete Lagoas: Embrapa-CNPMS. 8p. (Circular Técnica 154).

DEACON JW. 1997. Modern mycology. 3.ed. Oxford: Blackwell Science. 312p.

DEL RIO L.1990. Maiz muerto en Honduras provocado por el complejo Diplodia y Fusarium. Manejo Integrado de Plagas 18: 42-53.

DODD JL. 1980a. Grain Sink and Predisposition of Zea mays to Stalk Rot. Phytopathology 70: 534-535.

DODD JL. 1980b. The role of plant stresses in development of corn stalk rots. Plant Disease 64: 533-537.

FANCELLI AL. 1994. Milho e feijão: elementos para manejo em agricultura irrigada. Piracicaba: Departamento de agricultura/ESALQ/USP. 14p.

FOLEY DC \& WERNHAM CC. 1957. The effect of fertilizers on stalk rot of corn in Pennsylvania. Phytopathology 47: 11-12.

GATCH EW \& MUNKVOLD GP. 2002. Fungal species composition in maize stalks in relation to European corn borer injury and transgenic insect protection. Plant Disease 86: 1156-1162.

LEOPOLD AC. 1961. Senescence in plant development. Science 134: 1722-1732.

MARCHÃO RL et al. 2005. Densidade de plantas e características agronômicas de híbridos de milho sob espaçamento reduzido entre linhas. Pesquisa Agropecuária Tropical 35: 93-101.

MARCONDES MM. 2012. Incidência de podridão de colmo e grãos ardidos em híbridos de milho sob diferentes densidades de plantas e épocas de colheita. Dissertação (Mestrado em Produção Vegetal). Guarapuava: Unicentro. $62 \mathrm{p}$.

NELSON PE et al. 1983. Fusarium species: an illustrated manual for identification. University Park: Pennsylvania State University Press. 226p.

PEIXOTO CM et al. 1997. Produtividade de híbridos de milho em função da densidade de plantas, em dois níveis de manejo da água e da adubação. Pesquisa Agropecuária Gaúcha 3: 63-71.

R DEVELOPMENT CORE TEAM. 2014. R: A language and environment for statistical computing. R Foundation for Statistical Computing. URL http://www.R-project.org/. REIS EM et al. 1998. Método para quantificar os danos no rendimento de grãos causados pelas podridões da base do colmo do milho. Fitopatologia Brasileira 23: 300. (Suplemento).

RIBEIRO NA et al. 2005. Incidência de podridões do colmo, grãos ardidos e produtividade de grãos de genótipos de milho em diferentes sistemas de manejo. Ciência Rural 35: 1003-1009. 
SANGOI L \& SILVA PRF. 2010. Arranjo de plantas e desempenho agronômico do milho. In: WORDELL FILHO JÁ \& ELIAS HT (Org.). A cultura do milho em Santa Catarina. 1.ed. Florianópolis: Epagri. p.115-161.

SERPA MS et al. 2008. Redução do espaçamento entre linhas no milho na época de semeadura do cedo da Depressão Central do Rio Grande do Sul. In: 53 Reunião Técnica Anual de Milho. Atas e Resumos... Pelotas: Embrapa. (CD-Rom).

SHURTLEFF MC. 1992. Compendium of corn diseases. St. Paul: American Phytopathological Society. 105p.

TETIO-KAGHO F \& GARDNER FP. 1988. Responses of maize to plant population density. II. Reproductive development, yield and yield adjustments. Agronomy Journal 80:935-940.

WORDELL FILHO JA \& CASA RT. 2010. Doenças na cultura do milho. In: WORDELL FILHO JA \& ELIAS HT (Eds.). A cultura do milho em Santa Catarina. Florianópolis: Epagri. p.207-272.

WORDELL FILHO JA \& SPAGNOLLO E. 2013. Sistema de cultivo e doses de nitrogênio na sanidade e no rendimento do milho. Ciência Rural 43:199-205.

ZUBER MS et al. 1957. Studies of the interrelation of field stalk lodging, two stalk rotting fungi, and chemical composition of corn. Journal of Agricultural Research 49: 328-331. 